Planets and Satellites, Volume III of The Solar System, edited by Gerard P. Kuiper and Barbara M. Middlehurst. Published by the University of Chicago Press, Chicago, Illinois, 1961. Price $\$ 12.50$.

This third volume of the series on the solar system lives up to the high standard set by its predecessors. As noted by the editors, "the bulk of this volume is concerned with basic data whose value may be regarded as essentially permanent." Contains: The Planet Earth as Seen from Space (Fritz and Wexler), The Trans-Neptunian Planet Search (Tombaugh), Orbits and Masses of Planets and Satellites (Brouwer and Clemence), The Stability of the Solar System (Hagihara), Planetary Interiors (Wildt), Photometry of the Moon (Minnaert), Photometry of Lunar Eclipses (Barbier), Photometry and Colorimetry of Planets and Satellites (Harris), Polarization Studies of Planets (Dollfus), Planetary Temperature Measurements (Pettit), Recent Radiometric Studies of the Planets and the Moon (Sinton), Radio Emission of the Moon and Planets (Mayer), Radio Observations of Jupiter. I (Burke), Radio Observations of Jupiter. II (Gallet), Visual and Photographic Studies of Planets at the Pic du Midi (Dollfus), Photographs of Planets with the 200-inch Telescope (Humason), Color Photographs of Mars (Finsen), Limits of Completeness (Kuiper).

Aeronautics and Astronautics: An American Chronology of Science and Technology in the Exploration of Space, 1915-1960, by Eugene M. Emme. Published by the National Aeronautics and Space Administration, 1961. Obtainable from U. S. Government Printing Office, Washington, D. C. Price $\$ 1.75$.

Bare chronological tabulation of simple facts, dates, and events of the development of aircraft and spacecraft throughout the world. Table of satellites through 1960.

Peacetime Uses of Outer Space, edited by Simon Ramo. Published by the McGraw-Hill Book Company, New York. Price $\$ 6.95$.

A series of thoughtful, semipopular analyses of problems in the use of space, by leading experts such as Goldberg, Kaplan, Libby, and Hayward. Many of these symposium articles are simultaneously careful and imaginative enough to be likely to remain both valuable and interesting for some years to come.

\title{
NOTICE
}

\section{U. S. and U.S.S.R. Academy of Sciences Research Scientist Agreement}

$T^{\mathrm{H}}$ HE U. S. National Academy of Sciences and the Academy of Sciences of the U.S.S.R. have announced the signing of a new and enlarged agreement on the exchange of visits by research scientists of each country. Signed by the presidents of the U. S. and Soviet Academies-Detlev W. Bronk and M. V. Keldysh, respectively - the new compact will be in effect for two years as an annex to a general agreement on cultural exchanges signed by representatives of the two governments on March 8.

While the first agreement, signed in 1959, gave each side the opportunity to send 44 scientists on individual visits of varying length totaling 70 months, the new agreement will enable each Academy to send 55 scientists for a total of 180 months over the two-year period. Greatest increase has been in long-term visits (5 to 10 months) for the conduct of research; these are expected to appeal especially to younger scientists.

The specific exchange provisions are as follows: Twenty distinguished scientists from each country, at least half of whom are members of their respective Academies, to deliver lectures in the other country; Ten scientists from each country to make one-month visits to familiarize themselves with work in the other country; Four to six scientists from each country to conduct short-term projects in the other country lasting up to three months; Twenty scientists from each coun- try to conduct research in the other country for periods of five to ten months.

Under the new agreement, each Academy pledges to do what it can to facilitate the acceptance by its own nationals of invitations from the other country. The 1959 agreement did not provide for the issuance of invitations to individual scientists, and the new provision is intended to improve this aspect of exchanges.

In addition, the section of the old agreement regarding the exchange of invitations to national scientific meetings has been reworded in the hope that it will provide greater opportunities for American scientists to attend such meetings in the U.S.S.R.

In the United States, the success of the exchange program will continue to depend on the generous cooperation of American universities and scientific institutions participating in such exchanges-by granting leave to their faculty and staff members and by receiving Soviet scientists visiting this country under the auspices of the agreement.

These exchanges supplement other such scientific exchanges taking place between the U. S. and the Soviet Union, arranged by individual scientists and universities of each nation. There is no intention that the interAcademy agreements be considered exclusive instruments for the arrangement of such exchanges. 